\title{
Spotlight on afatinib and its potential in the treatment of squamous cell lung cancer: the evidence so far
}

This article was published in the following Dove Press journal:

Therapeutics and Clinical Risk Management

24 May 2016

Number of times this article has been viewed

\author{
Yijun $X u^{1,2}$ \\ Vivianne W Ding' \\ Hong Zhang ${ }^{2}$ \\ Xun Zhang ${ }^{2}$ \\ David Jablons' \\ Biao $\mathrm{He}^{\prime}$ \\ 'Thoracic Oncology Program, \\ Department of Surgery, Helen Diller \\ Family Comprehensive Cancer Center, \\ University of California San Francisco, \\ San Francisco, CA, USA; ${ }^{2}$ Tianjin \\ Chest Hospital, Tianjin, People's \\ Republic of China
}

\begin{abstract}
Compared to adenocarcinoma, fewer effective treatment options are available for advanced or metastatic squamous cell carcinoma (SCC) of the lung. Afatinib is an orally administered, irreversible EGFR antagonist. As a second-generation tyrosine kinase inhibitor, it has been applied in the treatment of patients with EGFR-mutant non-small-cell lung cancer. Recently, several clinical trials have shown that afatinib leads to a significant improvement in progression-free survival and overall survival of patients with SCC. Moving forward, afatinib should be one of the options among tyrosine kinase inhibitors, monoclonal antibodies, and cytotoxicity chemotherapy drugs for SCC.
\end{abstract}

Keywords: afatinib, squamous cell carcinoma, EGFR, tyrosine kinase inhibitor, non-small-cell lung cancer, ErbB

\section{Introduction}

Lung cancer remains the leading cause of cancer deaths for both males and females in the US, with an estimated 221,200 new cases and an estimated 158,040 deaths from the disease in 2015. Among ten leading cancer types, lung cancer ranks number one for mortality for both sexes, $28 \%$ in males and $26 \%$ in females. Despite major research efforts, overall survival (OS) remains dismally low, as only $18 \%$ of all patients with lung cancer are expected to survive 5 years after diagnosis. ${ }^{1}$ Non-small-cell lung cancer (NSCLC) accounts for $\sim 85 \%$ of lung tumor diagnoses. About $20 \%-30 \%$ of NSCLC cases are squamous cell carcinomas (SCCs). ${ }^{2}$ Due to its strong association with smoking, SCC used to be the most common NSCLC subtype, though its relative incidence rate reduces as smoking behavior changes. ${ }^{3}$ For patients with early-stage disease, treatment options for SCC and other subtypes of NSCLC are very similar. Patients without metastatic mediastinal lymph nodes should go through surgical evaluation, and some should receive adjuvant chemotherapy after resection of the primary lesions. ${ }^{4}$ Unfortunately, many NSCLC patients succumb to metastatic disease or progressed disease after local treatment surgery or radiotherapy. In the past decade, the discovery of the so-called driver gene mutations such as the mutations of EGFR and ALK have led to some drastic improvement in personalized targeted therapy for metastatic lung adenocarcinoma. ${ }^{5-7}$ However, no such serviceable molecular target exists for SCC. Patients with SCC are treated with widely used platinumbased chemotherapy. Therapies recently developed for lung adenocarcinoma such as pemetrexed, bevacizumab, and EGFR tyrosine kinase inhibitors (TKIs) are unsuitable for or mostly ineffective in lung SCC. ${ }^{8-10}$ For these reasons, the identification of
Correspondence: Biao He Thoracic Oncology Program, Department of Surgery, Helen Diller Family Comprehensive Cancer Center, University of California San Francisco, 2340 Sutter Street, San Francisco, CA 94115 , USA

$\mathrm{Tel}+\mathrm{I} 4154766907$

Email biao.he@ucsfmedctr.org 
effective molecular target for drug therapy of SCC is a top research task.

Afatinib is a second-generation EGFR TKI, which is able to block EGFR, HER2, and HER4 kinases covalently and irreversibly. ${ }^{11}$ To date, it has demonstrated properties to be developed into a hopeful therapeutic for two main diseases, NSCLC and head and neck SCC. ${ }^{12,13}$ In 2013, it was approved as a first-line treatment for metastatic NSCLC with common EGFR mutations. ${ }^{14,15}$ The purpose of this article is to focus on the role of afatinib in the therapy of SCC.

\section{The profile of afatinib and EGFR family}

Afatinib (Gilotrif ${ }^{\circledR}$, BIBW 2992) is an ATP-competitive anilinoquinazoline derivative harboring a reactive acrylamide group, competent for covalent binding to and irreversible blocking of EGFR, HER2, and HER 4. ${ }^{16}$ The chemical name of afatinib is 2-butenamide, $N$-[4-[(3-chloro-4-fluorophenyl) amino]-7-[[(3S)-tetrahydro-3-furanyl]oxy]-6-quinazolinyl]4-(dimethylamino)-,(2E)-,(2Z)-2-butenedioate(1:2), and it has a chemical structural formula of $\mathrm{C}_{32} \mathrm{H}_{33} \mathrm{CIFN}_{5} \mathrm{O}_{11}$ (Figure 1). ${ }^{17,18}$

EGFRs form a subgroup of the receptor tyrosine kinase family which includes four members: EGFR (HER1/ErbB1), HER2/ErbB2, HER3/ErbB3, and HER4/ErbB4. Every EGFR family member contains an extracellular binding domain, a transmembrane region, and a cytoplasmic tyrosine kinase domain. These receptors are activated by ligand binding, and the activation stimulates several intracellular signaling pathways. Two of these, the MAPK pathway and the PI3KAKT pathway, play very important roles in tumorigenesis. ${ }^{19}$ Activation of the MAPK and PI3K-AKT pathways leads to many downstream events, such as self-sufficient growth,

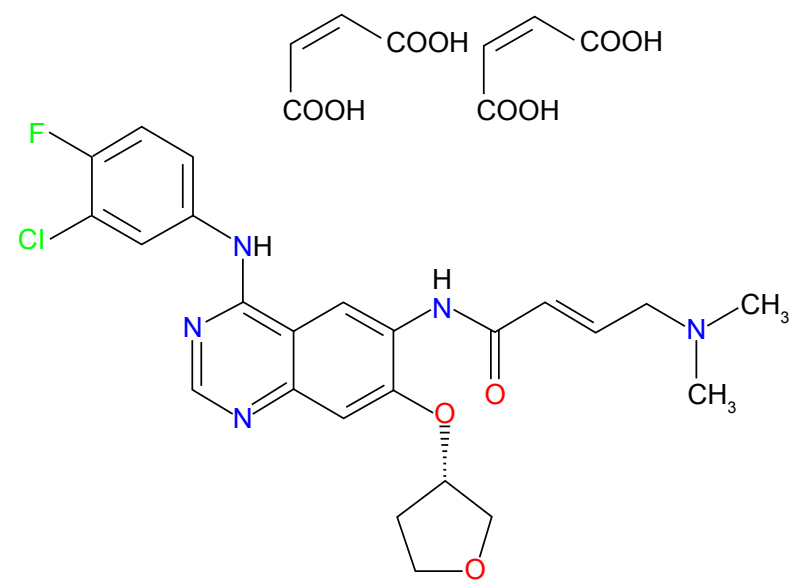

Figure I Afatinib chemical structure. insensitivity to antigrowth signals, escape from apoptosis, sustained angiogenesis, metastasis, and tissue invasion. In most cases, the upregulation of cell signaling is caused by activating mutations within the coding region of the receptor that subsequently induces a ligand-independent activation of the tyrosine kinase (Figure 2). ${ }^{18,20}$

\section{Afatinib and NSCLC}

In several preclinical studies, afatinib has been shown to be more effective in suppressing the tyrosine kinase activity of both wild-type and activated EGFR or HER2 mutants in cellfree kinase assays as well as in lung cancer cell lines. These afatinib-sensitive cancer cell lines contain erlotinib-resistant RTK isoforms, wild-type EGFR, L858R/T790M double mutation, or HER2 overexpression. ${ }^{21,22}$ These studies paved the way for Phase I studies which established the safe dosage of afatinib to be 40-50 mg per day orally for subsequent clinical trials. ${ }^{11}$ The most notable clinical trials that focused on afatinib were the LUX-Lung studies 1-8, which were sponsored by Boehringer Ingelheim (Table 1).

LUX-Lung 1 was a Phase IIB/III study that compared the benefit of afatinib plus best supportive care (BSC) versus placebo plus BSC. In this study, the recruited stage IIIB/IV adenocarcinoma patients all had disease progression after receiving a platinum doublet treatment first and then a first-generation TKI for at least 12 weeks. Afatinib was applied as a third-line or fourth-line therapy. ${ }^{23}$ A total of 585 patients were enrolled, in which 141 patient tissue samples were analyzed. Although this study did not require the presence of EGFR mutations, there were 96 (68\%) patients with EGFR mutations. Unfortunately, the study failed to show an OS benefit because of a higher median OS in the placebo arm. Median progression-free survival (PFS) was longer for patients with EGFR mutations treated with afatinib (3.3 months) than for those treated with placebo (1.1 months). The lack of a significant difference in OS between the two groups might have been the result of various subsequent treatments. Two hundred and fifty-seven (68\%) patients in the afatinib group and $153(79 \%)$ patients in the placebo group all underwent further treatments. However, an improved OS (5.8 months in afatinib group and 4.6 months in placebo group, hazard ratio [HR] 0.65) was shown in a post hoc analysis, in which the placebo group was controlled for no subsequent anticancer therapies. ${ }^{24}$ Meanwhile, in this trial, afatinib plus BSC significantly improved cancer-related symptoms such as cough, dyspnea, fatigue, and pain, as well as physical functioning and health-related quality of life (HRQoL). ${ }^{25}$ 


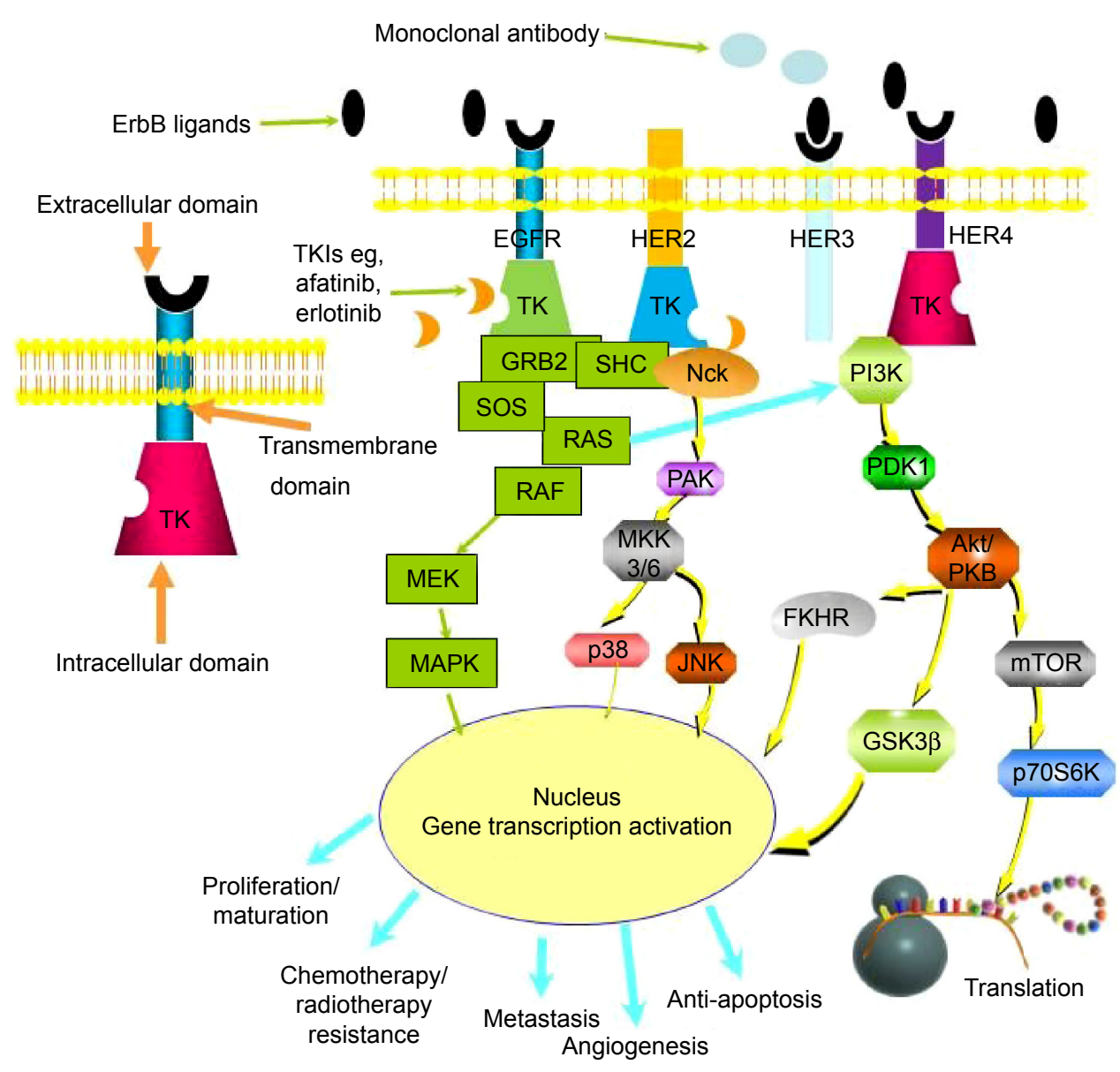

Figure 2 The EGFR family and ErbB family target network.

Abbreviation: TKI, tyrosine kinase inhibitor.

LUX-Lung 2, as a Phase II study, evaluated response rates in EGFR inhibitor-naïve patients with EGFR-mutant metastatic NSCLC in both the first-line and second-line settings. A total of 129 patients were enrolled in this study, among whom 99 received $50 \mathrm{mg}$ afatinib daily and 30 received $40 \mathrm{mg}$ daily. The results showed that patients harboring the two common sensitizing EGFR mutations (exon 19 deletion or L858R) demonstrated a higher response rate $(66 \%, 70$ of 106) compared to those patients with less common mutations (39\%, nine of 23$).{ }^{12}$ Although no significant difference in response rate was found between the two dosing groups (40 and $50 \mathrm{mg}$ daily), the toxicities of afatinib (diarrhea and rash) were notably lower in the patients who received $40 \mathrm{mg}$ daily. Because of this benefit, the dose of $40 \mathrm{mg}$ per day of afatinib was chosen for subsequent Phase III studies. ${ }^{24}$

LUX-Lung 3 and LUX-Lung 6 were two large randomized Phase III trials that focused on patients with EGFRmutant advanced lung adenocarcinoma who underwent up to six cycles of standard platinum doublet chemotherapy as the first-line treatment. ${ }^{26}$ Afatinib was compared with platinum-based doublet chemotherapy as second-line treatment in 345 patients in LUX-Lung 3 and 364 patients in LUXLung 6. In LUX-Lung 3 study, pemetrexed/cisplatin was used as the control arm, while gemcitabine/cisplatin was used as the control arm in the LUX-Lung $6 .{ }^{26}$ LUX-Lung 3 enrolled patients all over the world, and LUX-Lung 6 was performed in East Asia. LUX-Lung 3 presented an advantage of PFS of 11.1 versus 6.9 months (HR $0.58,95 \%$ confidence interval [CI] $0.43-0.78, P=0.001$ ) when afatinib was compared with the control arm. Furthermore, in patients whose cancers had common EGFR mutations (exon 19 deletion or L858R), this PFS difference was markedly greater (13.6 versus 6.9 months; HR $0.47,95 \%$ CI $0.34-0.65, P=0.001)$. Also in LUX-Lung 6, it was reported that afatinib presented a PFS of 11.0 versus 5.6 months with the platinum doublet chemotherapy arm (HR 0.28, $P=0.0001$ ) ${ }^{27,28}$ However, both the trials failed to show a benefit of OS. A pooled analysis of LUX-Lung 3 and LUX-Lung 6, reported at the 2014 American Society of Clinical Oncology meeting, presented an OS advantage of 3 months for patients who were administered afatinib 


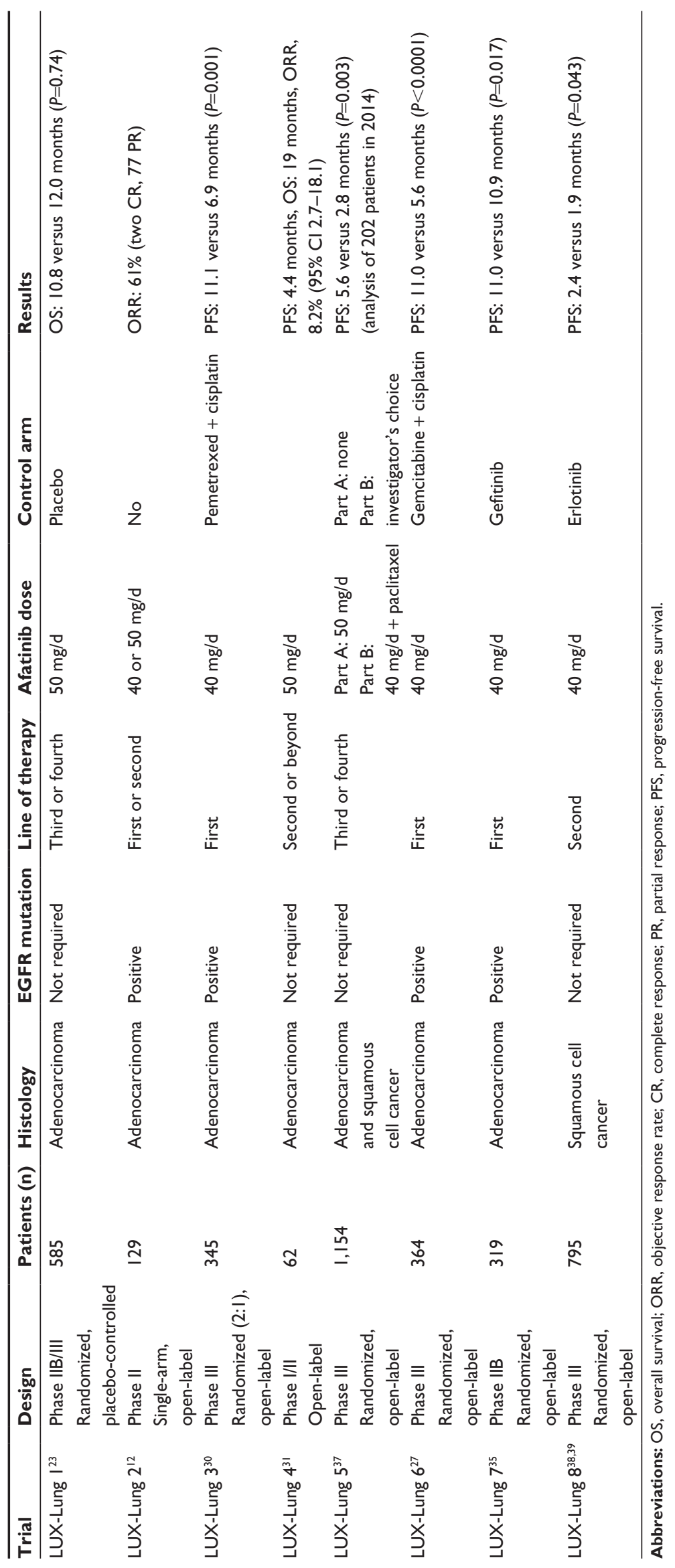


compared with the chemotherapy control arm. ${ }^{17,29}$ In total, 631 of 709 patients with EGFR common mutations (exon 19 deletions or L858R) involved in the two studies were analyzed in the pooled analysis. A small but statistically significant increase in OS was observed in the afatinib-treated arm (27.3 versus 24.3 months in the chemotherapy arm; HR 0.81, $P=0.037$ ). Interestingly, afatinib treatment allowed patients with EGFR Del19 mutations to have a median OS of 31.7 months (HR 0.59 , 95\% CI $0.45-0.77, P<0.001$ ), whereas OS was not improved for patients with EGFR L858R mutations (HR 1.25, 95\% CI 0.92-1.71, $P=0.160$ ). Overall, in both the trials, the median OS was higher among patients with exon 19 deletion. ${ }^{30}$

LUX-Lung 4 was a Phase II single-arm study, which enrolled patients with advanced lung adenocarcinoma whose disease progressed after at least 12 weeks of prior gefitinib and/or erlotinib in Japan. ${ }^{31}$ A total of 62 patients were recruited, and 61 were analyzed in this study. Fifty-one $(82.3 \%)$ of these patients had acquired resistance to firstgeneration EGFR TKIs, and 45 (72.6\%) had EGFR mutation in their primary lung cancer. The results showed that the median PFS was 4.4 months (95\% CI 2.8-4.6); meanwhile, the median OS was 19.0 months. Five patients had a confirmed partial response according to the evaluation criteria in solid tumors (RECIST). Two patients with a secondary T790M mutation (L858R plus T790M and exon 19 deletion plus T790M) who met the resistance criteria achieved stable disease for 9 months and 1 month, respectively. This trial presented a moderate activity of afatinib in patients whose lung cancers were heavily pretreated.

LUX-Lung 5 study was a randomized Phase III trial, which assessed the benefit of afatinib in combination with chemotherapy in patients who were previously treated with chemotherapy and/or a first-generation EGFR inhibitor (gefitinib/erlotinib). ${ }^{32}$ This study was divided into two parts. In part $\mathrm{A}$, all patients were initially treated with $50 \mathrm{mg}$ of afatinib per day until the disease progressed. Those who received afatinib for 12 weeks or longer went into part $B$. Patients were randomized 2:1 into afatinib/paclitaxel combination treatment group (40 mg per day; $80 \mathrm{mg} / \mathrm{m}^{2}$ per week) or mono-chemotherapy-alone group (chemotherapy agent per investigator's choice). In 202 patients analyzed in 2014, combination treatment arm showed an increased PFS when compared with chemotherapy-alone arm (5.6 versus 2.8 months; HR $0.60,95 \%$ CI $0.43-0.85, P=0.003)$. The objective response rate (ORR) was also significantly higher in the combination arm $(32.1 \%$ versus $13.2 \%, P=0.005)$. However, the OS presented a similar status in both arms
(12.2 versus 12.2 months; HR 1.00, 95\% CI 0.70-1.43, $P=0.994)$. Meanwhile, the afatinib-related toxicities, such as diarrhea, asthenia, and alopecia, were observed at a higher incidence in the combination therapy group. Overall, the results of this trial indicated that those cancers that progressed on TKIs treatment continue to rely on signaling through the EGFR family. Patients can probably benefit from continuous EGFR family inhibition, although further studies are needed to confirm this theory. ${ }^{32}$

LUX-Lung 7 (ClinicalTrials.gov Identifier: NCT01466660) was a Phase IIB trial of afatinib versus gefitinib as a firstline treatment for EGFR mutation-positive adenocarcinoma of the lung. It involved 319 patients with advanced lung adenocarcinoma that was staged IIIB/IV and positive for common EGFR mutations (Del19/L858R). Patients were divided into two groups randomly, afatinib compared with gefitinib (given orally daily). The primary outcome measures were PFS, time to treatment failure, and OS. The secondary outcome measures were objective response, duration of disease control, tumor shrinkage, and HRQoL. ${ }^{33}$ Recent analysis shows that regarding PFS, time to treatment failure, ORR, and duration of response, there is a slight trend in favor of afatinib. ${ }^{34,35}$ These results will be very important for the registration strategy for afatinib and for the selection criteria of optimal EGFR TKI as the first-line treatment for cancers with EGFR mutation. ${ }^{24}$

\section{Afatinib and SCC}

In LUX-Lung 5, among the 1,154 enrolled patients, $90(7.8 \%)$ had SCC histology and received afatinib in part A of the trial. Median PFS and ORR were 3.7 months and $6 \%$, respectively. There were $17(8.4 \%)$ patients meeting the criteria for part B of the trial, who were randomized (2:1) into afatinib/paclitaxel $(n=11)$ or chemotherapy-alone $(n=6)$ arms. The results showed that median PFS was 8.8 months in the afatinib/paclitaxel group compared with 1.9 months in the investigator's choice group (HR 0.15, 95\% CI $0.03-0.62, P=0.003)$. Although a trend toward increased OS (14.9 versus 6.6 months, $P=0.433$ ) was observed, the number of patients involved was too few to draw any convincing conclusions. ${ }^{36,37}$

Among the LUX-Lung trials, LUX-Lung 8 was the only study that focused on SCC. The trial was initiated by the observation of ErbB mutation or overexpression in lung SCC. It was a second-line, Phase III study comparing afatinib and erlotinib in patients with advanced SCC who had progressed after at least four cycles of chemotherapy with platinum doublet agents. ${ }^{38}$ Patients who had prior treatment with 
EGFR TKI or antibody were excluded. In total, 795 eligible patients were randomized to two arms, 398 receiving afatinib $40 \mathrm{mg}$ per day and 397 receiving erlotinib $150 \mathrm{mg}$ per day. The primary end point measure was PFS, and secondary end points included ORR, OS, disease control rate, HRQoL, and safety. At the time of the primary analysis (median follow-up 18.4 months), median OS was significantly higher in the afatinib arm than the erlotinib arm (7.9 [95\% CI 7.2-8.7] versus 6.8 months [95\% CI 5.9-7.8]; HR 0.81, 95\% CI $0.69-0.95, P=0.0077)$, while median PFS was $2.6(95 \%$ CI 2.0-2.9) versus 1.9 months (95\% CI 1.9-2.1) (HR 0.81, 95\% CI $0.69-0.96, P=0.0103$ ) and DCR was 51\% (201 of 398 patients) versus $40 \%$ (157 of 397$)(P=0.0020)$. However, the percentage of patients with an objective response did not show any significant difference between the two groups (22 [6\%] versus 11 [3\%], $P=0.0551$ ). Tumor shrinkage took place in $103(26 \%)$ of 398 patients in afatinib arm versus $90(23 \%)$ of 397 patients in erlotinib arm. Adverse event (AE) profiles presented a similar status in each group: $224(57 \%)$ of 392 patients in the afatinib arm versus 227 (57\%) of 395 in the erlotinib arm had grade $\geq 3$ AE. For example, higher incidences of treatment-related grade 3 AEs were recorded, such as diarrhea (39 [10\%] for afatinib versus nine [2\%] for erlotinib) and stomatitis (16 [4\%] for afatinib versus none for erlotinib), whereas incidences of rash or acne were lower (23 [6\%] versus 41 [10\%] for erlotinib). ${ }^{39}$ These results suggest that afatinib could be an optional agent for the treatment of patients with SCC of the lung. Most recently, on April 15 2016, according to the results of LUX-Lung 8, the US Food and Drug Administration (FDA) approved Gilotrif ${ }^{\circledR}$ (afatinib) as a new oral treatment option for patients with SCC of the lung. ${ }^{40}$ However, some researchers are not impressed with the efficacy, as well as the toxicity, of afatinib in squamous NSCLC. Perhaps, ongoing and future studies could reveal other more effective therapies for this neoplasm, including immunotherapy. ${ }^{41}$

\section{Discussion}

Because EGFR mutations are rarely $(<5 \%)$ found in SCC of the lung, the inhibition of the progression of SCC tumors by TKIs may not be through mutated EGFRs. ${ }^{42}$ But expression levels of wild-type EGFR tend to be high in SCC. ${ }^{43,44}$ Previous studies of the EGFR TKI erlotinib showed improved clinical outcomes in patients with SCC, and resulted in approvals of erlotinib as the second-line and maintenance treatment. The efficacy of erlotinib in SCC population (HR 0.67, 95\% CI 0.50-0.90) was at least as impressive as that in adenocarcinoma (HR 0.71, 95\% CI 0.56-0.92). ${ }^{45,46}$
Two studies showed that afatinib is active against advanced NSCLC in patients who lack EGFR mutations but have an increased EGFR gene copy number by amplification or polysomy. ${ }^{47,48}$ However, the result of a post hoc analysis of LUX-Lung 8 paints a slightly different picture. ${ }^{39}$ According to the results of clinical benefit achieved with afatinib or erlotinib, a subgroup of 238 patients was selected and divided into presumed treatment benefit group (PFS $>2$ months; $\mathrm{n}=144$ ) and treatment-refractory group (PFS $\leq 2$ months; $\mathrm{n}=94)$. The percentage of patients with EGFR mutations was overall low (14 [6\%]) in this study. Also, only 15 patients had EGFR amplification (6\%; nine in afatinib group and six in erlotinib group). The findings implied that the improvement of survival outcomes with afatinib in this study probably was not driven by EGFR molecular aberrations. These clinical benefits might have been a consequence of afatinib's higher, wider, and stronger irreversible inhibition of ErbB.

Some studies demonstrated that the clinical efficacy of afatinib in patients without EGFR mutations may be due to the suppression of compensatory signaling through other ErbB family members. Twenty-five percent of NSCLCs express HER2, within which roughly $5 \%$ of cases have substantial overexpression and these are all SCC cases. ${ }^{49,50}$ HER3 overexpresses in $\sim 30 \%$ of SCCs. ${ }^{51}$ In addition, a comprehensive analysis of SCCs recognized genetic aberrations in HER2 (4\%) and HER3 (2\%), as well as in several downstream signaling molecules of the ErbB receptors: BRAF (4\%), RASA1 (4\%), KRAS (3\%), HRAS (3\%), NF1 (11\%), and in NRG1. ${ }^{52}$ These findings implied that afatinib inactivates multiple aberrant signaling cascades downstream of ErbB receptors possibly via its ability to inhibit receptor dimerization in SCC. ${ }^{53}$

Another possible mechanism of afatinib has been shown in NSCLC cell lines H358 and H441, which lack EGFR mutations. The apoptotic effect of afatinib on cancer cells is associated with downregulation of CIP2A, upregulation of PP2A activity, and reduction in AKT phosphorylation. Afatinib downregulates CIP2A at the gene transcription level by decreasing the promoter-binding activity of Elk-1. In vivo potency of afatinib against xenograft tumors was also confirmed in nude mice NSCLC models. ${ }^{54}$ Interestingly, ELK1 is overexpressed in SCC, and ELK1 overexpression is associated with a poor prognosis. ${ }^{55,56}$ Overall, targeting CIP2A is likely a potential mechanism of afatinib inhibiting SCC of the lung.

The safety of afatinib has been a potential weakness. Afatinib has almost the same toxicities as those of the firstgeneration EGFR TKIs, for example, gefitinib and erlotinib. Typical side effects include diarrhea, acne or rash, paronychia, 
stomatitis, nausea, and decreased appetite. Among these, diarrhea was the most frequent side effect in the LUX-Lung trials, and there were $17 \%-22 \%$ of patients with grade 3 diarrhea. ${ }^{22}$ In the LUX-Lung 6 trial, therapy was discontinued due to treatment-related AEs in $12 \%$ of patients who received chemotherapy and $8 \%$ of patients who received afatinib. ${ }^{27}$ The incidence of grade 3 diarrhea was higher than that reported with gefitinib or erlotinib in the LUX-Lung 3 and LUX-Lung 4 trials. ${ }^{26,31}$ It was reported that diarrhea, paronychia, and stomatitis were better with erlotinib than with afatinib; furthermore, for skin rash, no significant difference was observed in the severity or frequency. ${ }^{57}$ The incidence of gastrointestinal and dermatological toxicity in afatinib trials seemed to be more frequent than those reported in studies with erlotinib and gefitinib. ${ }^{58}$ However, these data mostly came from indirect comparisons except for the data from LUXLung 7 and LUX-Lung 8. In LUX-Lung 7, the severity and frequency of all-cause adverse effects were similar in both afatinib and gefitinib groups (158 [99\%] of 160 in the afatinib arm and 159 [100\%] of 159 in the gefitinib arm). Grade $\geq 3$ AEs were seen in $91(57 \%)$ in the afatinib arm and $83(52 \%)$ in the gefitinib arm. The most common drug-related grade $\geq 3$ adverse effects in patients with afatinib were diarrhea (20 $[13 \%])$, acne or rash (15 [9\%]), and fatigue (9 [6\%]), and in patients with gefitinib were increased alanine aminotransferase /aspartate aminotranferase (14 [9\%]) and acne or rash (5 [3\%]). Drug-related serious AEs were reported in 17 (11\%) patients with afatinib and seven (4\%) patients with gefitinib. ${ }^{35}$ In LUX-Lung 8, each group had a similar percentage of patients with AEs: 390 (99\%) of 392 in the afatinib arm versus $385(97 \%)$ of 395 in the erlotinib arm. The severity of AEs (grade $\geq 3$ ) was essentially the same in each arm (224 [57\%] versus 227 [57\%]). Even though 104 (27\%) of 392 patients in the afatinib group versus $56(14 \%)$ of 395 in the erlotinib group had dose reductions due to AEs, a similar number of patients discontinued treatment due to AEs (79 [20\%] versus $67[17 \%]) .{ }^{58}$ These results suggested that afatinib had acceptable treatment-related toxicity. Patients could receive clinical benefit, especially if dose reduction scheme is applied.

Erlotinib and docetaxel used to be the only two approved second-line therapeutic agents for SCC of the lung. ${ }^{59}$ Recently, several new drugs have been approved, one of which, ramucirumab (an anti-VEGFR-2 antibody), was approved by the FDA in 2014. Ramucirumab plus docetaxel has been used for treatment of NSCLC including SCC. In a sub-analysis of REVEL trial of patients with SCC, median OS was 9.5 months (range: 4.4-17.6 months) in 157 patients treated with ramucirumab plus docetaxel versus 8.2 months (range: 3.6-14.9 months) in 171 patients treated with docetaxel alone (HR 0.88, 95\% CI 0.69-1.13). ${ }^{60}$ Furthermore, a Phase II single-arm trial was conducted, in which 117 heavily pretreated patients (two or more prior treatments) with advanced SCC of the lung were treated with nivolumab (a PD-1 checkpoint inhibitor). In this trial, 17 (14.5\%) patients responded positively to the treatment (95\% CI 8.7-22.2), and $26(30 \%)$ patients had stable disease (95\% CI 4.7-10.9). Compared to typical median survival of $4.0-6.5$ months, the treated group had a median OS of 8.2 months (95\% CI 6.1-10.9). ${ }^{61}$ A Phase III study CheckMate-017 compared second-line nivolumab $(n=135)$ with docetaxel $(n=137)$ in patients with SCC of the lung. This trial was completed early because it met the primary end point of median OS (9.2 versus 6.0 months; HR $0.59,95 \%$ CI $0.44-0.79, P<0.001)$. Supported by these data, nivolumab was approved by the FDA for treatment of patients with metastatic SCC of the lung, who progressed during or after platinum-based chemotherapy. ${ }^{62}$ In addition, these changes to therapy for SCC of the lung might soon be extended to the first-line setting, based on the results from the SQUIRE trial. ${ }^{63}$ In this study, necitumumab (a human EGFR monoclonal antibody) was tested in combination with gemcitabine plus cisplatin, versus gemcitabine plus cisplatin alone, in patients with stage IV SCC of the lung. Median OS was significantly longer in the necitumumab combined arm than in the gemcitabine-cisplatin-alone arm (11.5 versus 9.9 months; stratified HR 0.84, 95\% CI 0.74-0.96, $P=0.01$ ).

Current observations indicate that we are in the promising era of seeing increasing survival improvements for a large group of SCC patients. Recent studies have suggested FGFR and $\mathrm{PI} 3 \mathrm{~K}-\mathrm{AKT}$ as future targets and a potential opportunity for VEGFR inhibition, which collectively should improve quality of life and survival of those patients with SCC over the next decade. ${ }^{64}$

Other endeavors to search for new treatment for SCC of the lung are underway. Among them, Lung-MAP (S1400) is unique. The Lung-MAP study is an umbrella study where every patient sample goes through a next-generation sequencing platform so that they can be placed into different specific target biomarker sub-studies. Patients are then randomized to either a targeted investigational drug treatment or a defined standard therapy. For those without a known or relevant biomarker target, there is an "unmatched" group, in which recruits receive an inhibitor of PD-L1 or chemotherapy. The Lung-MAP project brings together pharmaceutical companies, the National Cancer Institute, the FDA, and advocacy groups. ${ }^{65,66}$ If successful, the LungMAP will provide a rapid path for FDA approval of new 
Table 2 Ongoing clinical trials of afatinib for tumors including SCC

\begin{tabular}{|c|c|c|c|c|c|c|}
\hline Clinical trials ID & $\begin{array}{l}\text { Study } \\
\text { phase }\end{array}$ & Tumor & Patients & Treatment & $\begin{array}{l}\text { Enrollment } \\
\text { (n) }\end{array}$ & $\begin{array}{l}\text { Primary outcome } \\
\text { measures }\end{array}$ \\
\hline NCT0227I906 & Phase II & NSCLC & $\begin{array}{l}\text { Stage IA-IIB or resectable } \\
\text { stage IIIA disease }\end{array}$ & $\begin{array}{l}40 \mathrm{mg} / \mathrm{d} \text { for a minimum } \\
\text { of } 14 \text { days, and until } \\
\text { the day of surgery }\end{array}$ & 20 & $\begin{array}{l}\text { Ability to complete } \\
\text { treatment before } \\
\text { surgery }\end{array}$ \\
\hline NCT02I 45637 & Phase I & NSCLC & Stage 4 & $\begin{array}{l}\text { Afatinib plus ruxolitinib } \\
\text { combination }\end{array}$ & 60 & $\begin{array}{l}\text { Set a recommended } \\
\text { Phase II dose }\end{array}$ \\
\hline NCT02020577 & Phase I & Solid tumor & $\begin{array}{l}\text { Advanced malignant solid } \\
\text { tumors that are metastatic } \\
\text { or unresectable }\end{array}$ & $\begin{array}{l}\text { Afatinib once-daily } \\
\text { plus weekly cetuximab } \\
\text { infusion }\end{array}$ & 58 & $\begin{array}{l}\text { Maximum tolerated } \\
\text { dose as defined } \\
\text { by dose-limiting } \\
\text { toxicity }\end{array}$ \\
\hline NCTOII 56545 & Phase II & NSCLC & $\begin{array}{l}\text { Stage IIIB or IV } \\
\text { non-adenocarcinomatous } \\
\text { non-small-cell lung cancer }\end{array}$ & $\begin{array}{l}\text { Afatinib plus simvastatin } \\
\text { versus afatinib }\end{array}$ & 84 & $\begin{array}{l}\text { Objective response } \\
\text { rate }\end{array}$ \\
\hline
\end{tabular}

Abbreviations: SCC, squamous cell carcinoma; NSCLC, non-small-cell lung cancer.

drugs in lung cancer therapy. This clinical trial approach can be extended to other tumor types and to other countries as well. ${ }^{67}$ Furthermore, several other ongoing studies of afatinib on tumors including SCC of the lung can be found on the ClinicalTrials website (Table 2). ${ }^{68}$

In summary, following the results of recent clinical studies, it is promising that patients with SCC will have more and more treatment options in the event that first-line therapy becomes unsuccessful. Afatinib should be one of the options among TKIs, monoclonal antibodies, and cytotoxicity chemotherapy drugs, depending on the molecular nature of the individual patient. We look forward to future evidence to support afatinib as an effective therapeutic agent targeting SCC of the lung.

\section{Disclosure}

The authors declare no conflicts of interest in this work.

\section{References}

1. Siegel RL, Miller KD, Jemal A. Cancer statistics, 2015. CA Cancer J Clin. 2015;65(1):5-29.

2. Hall PE, Spicer J, Popat S. Rationale for targeting the ErbB family of receptors in patients with advanced squamous cell carcinoma of the lung. Future Oncol. 2015;11(15):2175-2191.

3. Gold KA, Wistuba II, Kim ES. New strategies in squamous cell carcinoma of the lung: identification of tumor drivers to personalize therapy. Clin Cancer Res. 2012;18(11):3002-3007.

4. Arriagada R, Bergman B, Dunant A, Le Chevalier T, Pignon JP, Vansteenkiste J. Cisplatin-based adjuvant chemotherapy in patients with completely resected non-small-cell lung cancer. N Engl J Med. 2004; 350(4):351-360.

5. Roengvoraphoj M, Tsongalis GJ, Dragnev KH, Rigas JR. Epidermal growth factor receptor tyrosine kinase inhibitors as initial therapy for non-small cell lung cancer: focus on epidermal growth factor receptor mutation testing and mutation-positive patients. Cancer Treat Rev. 2013; 39(8):839-850.

6. Kwak EL, Bang YJ, Camidge DR, et al. Anaplastic lymphoma kinase inhibition in non-small-cell lung cancer. $N$ Engl J Med. 2010;363(18): 1693-1703.
7. Normando SR, Cruz FM, Del Giglio A. Cumulative meta-analysis of epidermal growth factor receptor-tyrosine kinase inhibitors as first-line therapy in metastatic non-small-cell lung cancer. Anticancer Drugs. 2015; 26(9):995-1003.

8. Johnson DH, Fehrenbacher L, Novotny WF, et al. Randomized phase II trial comparing bevacizumab plus carboplatin and paclitaxel with carboplatin and paclitaxel alone in previously untreated locally advanced or metastatic non-small-cell lung cancer. J Clin Oncol. 2004; 22(11):2184-2191.

9. Hanna N, Shepherd FA, Fossella FV, et al. Randomized phase III trial of pemetrexed versus docetaxel in patients with non-small-cell lung cancer previously treated with chemotherapy. J Clin Oncol. 2004; 22(9):1589-1597.

10. Scagliotti GV, Parikh P, von Pawel J, et al. Phase III study comparing cisplatin plus gemcitabine with cisplatin plus pemetrexed in chemotherapy-naive patients with advanced-stage non-small-cell lung cancer. J Clin Oncol. 2008;26(21):3543-3551.

11. Yap TA, Vidal L, Adam J, et al. Phase I trial of the irreversible EGFR and HER2 kinase inhibitor BIBW 2992 in patients with advanced solid tumors. J Clin Oncol. 2010;28(25):3965-3972.

12. Yang JC, Shih JY, Su WC, et al. Afatinib for patients with lung adenocarcinoma and epidermal growth factor receptor mutations (LUX-Lung 2): a phase 2 trial. Lancet Oncol. 2012;13(5):539-548.

13. Machiels JP, Haddad RI, Fayette J, et al. Afatinib versus methotrexate as second-line treatment in patients with recurrent or metastatic squamous-cell carcinoma of the head and neck progressing on or after platinum-based therapy (LUX-Head \& Neck 1): an open-label, randomised phase 3 trial. Lancet Oncol. 2015;16(5):583-594.

14. O'Connor K. FDA approves GILOTRIFTM (afatinib) as first-line treatment for metastatic non-small cell lung cancer with common EGFR mutations. 2013. Available from: http://us.boehringer-ingelheim.com/ news_events/press_releases/press_release_archive/2013/07-12-13-fdaapproves-gilotrif-afatinib-first-line-treatment-metastatic-non-smallcell-lung-cancer-common-egfr-mutations.html. Accessed May 17, 2016.

15. Dungo RT, Keating GM. Afatinib: first global approval. Drugs. 2013; 73(13):1503-1515.

16. Solca F, Dahl G, Zoephel A, et al. Target binding properties and cellular activity of afatinib (BIBW 2992), an irreversible ErbB family blocker. J Pharmacol Exp Ther. 2012;343(2):342-350.

17. Melosky B. Review of EGFR TKIs in metastatic NSCLC, including ongoing trials. Front Oncol. 2014;4:244.

18. Modjtahedi H, Cho BC, Michel MC, Solca F. A comprehensive review of the preclinical efficacy profile of the ErbB family blocker afatinib in cancer. Naunyn Schmiedebergs Arch Pharmacol. 2014;387(6):505-521.

19. Hynes NE, Lane HA. ERBB receptors and cancer: the complexity of targeted inhibitors. Nat Rev Cancer. 2005;5(5):341-354. 
20. Gazdar AF. Epidermal growth factor receptor inhibition in lung cancer: the evolving role of individualized therapy. Cancer Metastasis Rev. 2010; 29(1):37-48.

21. Li D, Ambrogio L, Shimamura T, et al. BIBW2992, an irreversible EGFR/HER2 inhibitor highly effective in preclinical lung cancer models. Oncogene. 2008;27(34):4702-4711.

22. Chen X, Zhu Q, Zhu L, et al. Clinical perspective of afatinib in nonsmall cell lung cancer. Lung Cancer. 2013;81(2):155-161.

23. Miller VA, Hirsh V, Cadranel J, et al. Afatinib versus placebo for patients with advanced, metastatic non-small-cell lung cancer after failure of erlotinib, gefitinib, or both, and one or two lines of chemotherapy (LUX-Lung 1): a phase 2b/3 randomised trial. Lancet Oncol. 2012; 13(5):528-538.

24. Yap TA, Popat S. Toward precision medicine with next-generation EGFR inhibitors in non-small-cell lung cancer. Pharmacogenomics Pers Med. 2014;7:285-295.

25. Hirsh V, Cadranel J, Cong XJ, et al. Symptom and quality of life benefit of afatinib in advanced non-small-cell lung cancer patients previously treated with erlotinib or gefitinib: results of a randomized phase IIb/III trial (LUX-Lung 1). J Thorac Oncol. 2013;8(2):229-237.

26. Sequist LV, Yang JC, Yamamoto N, et al. Phase III study of afatinib or cisplatin plus pemetrexed in patients with metastatic lung adenocarcinoma with EGFR mutations. J Clin Oncol. 2013;31(27): 3327-3334.

27. Wu YL, Zhou C, Hu C-P, et al. LUX-Lung 6: a randomized, openlabel, phase III study of afatinib (A) versus gemcitabine/cisplatin (GC) as first-line treatment for Asian patients (pts) with EGFR mutationpositive (EGFR M+) advanced adenocarcinoma of the lung. Paper presented at: ASCO Annual Meeting Proceedings; May 31-June 4, 2013; Chicago, IL.

28. Wu YL, Zhou C, Hu CP, et al. Afatinib versus cisplatin plus gemcitabine for first-line treatment of Asian patients with advanced non-small-cell lung cancer harbouring EGFR mutations (LUX-Lung 6): an open-label, randomised phase 3 trial. Lancet Oncol. 2014;15(2):213-222.

29. Yang JC-H, Sequist LV, Schuler MH, et al. Overall survival (OS) in patients (pts) with advanced non-small cell lung cancer (NSCLC) harboring common (Del19/L858R) epidermal growth factor receptor mutations (EGFR mut): pooled analysis of two large open-label phase III studies (LUX-Lung 3 [LL3] and LUX-Lung 6 [LL6]) comparing afatinib with chemotherapy (CT). Paper presented at: ASCO Annual Meeting Proceedings; May 30-June 4, 2014; Chicago, IL.

30. Yang JC, Wu YL, Schuler M, et al. Afatinib versus cisplatin-based chemotherapy for EGFR mutation-positive lung adenocarcinoma (LUX-Lung 3 and LUX-Lung 6): analysis of overall survival data from two randomised, phase 3 trials. Lancet Oncol. 2015;16(2): $141-151$.

31. Katakami N, Atagi S, Goto K, et al. LUX-Lung 4: a phase II trial of afatinib in patients with advanced non-small-cell lung cancer who progressed during prior treatment with erlotinib, gefitinib, or both J Clin Oncol. 2013;31(27):3335-3341.

32. Schuler MH, Yang C-H, Park K, et al. Continuation of afatinib beyond progression: results of a randomized, open-label, phase III trial of afatanib plus paclitaxel (P) versus investigator's choice chemotherapy (CT) in patients (pts) with metastatic non-small cell lung cancer (NSCLC) progressed on erlotinib/gefitinib (E/G) and afatanib - LUXLung 5 (LL5). Paper presented at: ASCO Annual Meeting Proceedings; May 30-June 4, 2014; Chicago, IL.

33. Heinmoller P, Gross C, Beyser K, et al. HER2 status in non-small cell lung cancer: results from patient screening for enrollment to a phase II study of herceptin. Clin Cancer Res. 2003;9(14):5238-5243.

34. Passaro A, Pochesci A, Spitaleri G, et al. Afatinib in first-line setting for NSCLC harbouring common EGFR mutations: new light after the preliminary results of LUX-Lung 7? J Thorac Dis. 2016;8(3): E217-E220.

35. Park K, Tan EH, O’Byrne K, et al. Afatinib versus gefitinib as first-line treatment of patients with EGFR mutation-positive non-small-cell lung cancer (LUX-Lung 7): a phase 2B, open-label, randomised controlled trial. Lancet Oncol. 2016;17(5):577-589.
36. Kim J-H, Grossi F, De Marinis F, et al. Afatinib monotherapy in patients with metastatic squamous cell carcinoma of the lung progressing after erlotinib/gefitinib (E/G) and chemotherapy: interim subset analysis from a phase III trial. J Clin Oncol. 2012;30(Suppl): abstr 7558.

37. Park K, Kim J, Schuler M, et al. Afatinib (A) followed by A+ paclitaxel (P) or investigator's choice of single-agent chemotherapy (IC) in patients (pts) with advanced squamous cell carcinoma (SCC) of the lung: subgroup analysis of LUX-Lung 5 (LL5). Ann Oncol. 2014;25(Suppl 4): iv443-iv444.

38. Goss G, Felip E, Cobo M, et al. A randomized, open-label, phase III trial of afatinib (A) vs erlotinib (E) as second-line treatment of patients (pts) with advanced squamous cell carcinoma (SCC) of the lung following first-line platinum-based chemotherapy: LUX-Lung 8 (LL8). Ann Oncol. 2014;25(Suppl 4):iv426.

39. Soria JC, Felip E, Cobo M, et al. Afatinib versus erlotinib as secondline treatment of patients with advanced squamous cell carcinoma of the lung (LUX-Lung 8): an open-label randomised controlled phase 3 trial. Lancet Oncol. 2015;16(8):897-907.

40. boehringer-ingelheim.com [homepage on the Internet]. FDA approves Gilotrif $^{\circledR}$ (afatinib) as new oral treatment option for patients with squamous cell carcinoma of the lung. 2016. Available from: http://us.boehringer-ingelheim.com/news_events/press_releases/ press_release_archive/2016/4-15-2016-fda-approves-gilotrif-afatiniboral-treatment-option-patients-squamous-cell-carcinoma-lung.html. Accessed April 15, 2016.

41. Lo Russo G, Proto C, Garassino MC. Afatinib in the treatment of squamous non-small cell lung cancer: a new frontier or an old mistake? Transl Lung Cancer Res. 2016;5(1):110-114.

42. Dearden S, Stevens J, Wu YL, Blowers D. Mutation incidence and coincidence in non small-cell lung cancer: meta-analyses by ethnicity and histology (mutMap). Ann Oncol. 2013;24(9):2371-2376.

43. Hirsch FR, Varella-Garcia M, Bunn PA, et al. Epidermal growth factor receptor in non-small-cell lung carcinomas: correlation between gene copy number and protein expression and impact on prognosis. J Clin Oncol. 2003;21(20):3798-3807.

44. Cappuzzo F, Hirsch FR, Rossi E, et al. Epidermal growth factor receptor gene and protein and gefitinib sensitivity in non-small-cell lung cancer. J Natl Cancer Inst. 2005;97(9):643-655.

45. Cappuzzo F, Ciuleanu T, Stelmakh L, et al. Erlotinib as maintenance treatment in advanced non-small-cell lung cancer: a multicentre, randomised, placebo-controlled phase 3 study. Lancet Oncol. 2010;11(6): 521-529.

46. Shepherd FA, Rodrigues Pereira J, Ciuleanu T, et al. Erlotinib in previously treated non-small-cell lung cancer. N Engl J Med. 2005;353(2): 123-132.

47. De Greve J, Moran T, Graas MP, et al. Phase II study of afatinib, an irreversible ErbB family blocker, in demographically and genotypically defined lung adenocarcinoma. Lung Cancer. 2015;88(1): 63-69.

48. Cappuzzo F, Finocchiaro G, Grossi F, et al. Phase II study of afatinib, an irreversible ErbB family blocker, in EGFR FISH-positive non-smallcell lung cancer. J Thorac Oncol. 2015;10(4):665-672.

49. Hirsch FR, Franklin WA, Veve R, Varella-Garcia M, Bunn PA Jr. HER2/neu expression in malignant lung tumors. Semin Oncol. 2002; 29(1 Suppl 4):51-58.

50. Ugocsai K, Mandoky L, Tiszlavicz L, Molnar J. Investigation of HER2 overexpression in non-small cell lung cancer. Anticancer Res. 2005; 25(4):3061-3066.

51. Yi ES, Harclerode D, Gondo M, et al. High c-erbB-3 protein expression is associated with shorter survival in advanced non-small cell lung carcinomas. Mod Pathol. 1997;10(2):142-148.

52. Cancer Genome Atlas Research Network. Comprehensive genomic characterization of squamous cell lung cancers. Nature. 2012;489(7417) 519-525.

53. Nelson V, Ziehr J, Agulnik M, Johnson M. Afatinib: emerging nextgeneration tyrosine kinase inhibitor for NSCLC. Oncotargets Ther. 2013;6:135-143. 
54. Chao TT, Wang CY, Chen YL, et al. Afatinib induces apoptosis in NSCLC without EGFR mutation through Elk-1-mediated suppression of CIP2A. Oncotarget. 2015;6(4):2164-2179.

55. Dong QZ, Wang Y, Dong XJ, et al. CIP2A is overexpressed in nonsmall cell lung cancer and correlates with poor prognosis. Ann Surg Oncol. 2011;18(3):857-865.

56. Xu P, Xu XL, Huang Q, Zhang ZH, Zhang YB. CIP2A with survivin protein expressions in human non-small-cell lung cancer correlates with prognosis. Med Oncol. 2012;29(3):1643-1647.

57. D'Arcangelo M, Hirsch FR. Clinical and comparative utility of afatinib in non-small cell lung cancer. Biol Targets Ther. 2014;8:183-192.

58. Giordano P, Manzo A, Montanino A, et al. Afatinib: an overview of its clinical development in non-small-cell lung cancer and other tumors. Crit Rev Oncol Hematol. 2016;97:143-151.

59. Reck M, Popat S, Reinmuth N, De Ruysscher D, Kerr KM, Peters S. Metastatic non-small-cell lung cancer (NSCLC): ESMO Clinical Practice Guidelines for diagnosis, treatment and follow-up. Ann Oncol. 2014;25 Suppl 3:iii27-iii39.

60. Garon EB, Ciuleanu TE, Arrieta O, et al. Ramucirumab plus docetaxel versus placebo plus docetaxel for second-line treatment of stage IV non-small-cell lung cancer after disease progression on platinum-based therapy (REVEL): a multicentre, double-blind, randomised phase 3 trial. Lancet. 2014;384(9944):665-673.

61. Rizvi NA, Mazieres J, Planchard D, et al. Activity and safety of nivolumab, an anti-PD-1 immune checkpoint inhibitor, for patients with advanced, refractory squamous non-small-cell lung cancer (CheckMate 063): a phase 2, single-arm trial. Lancet Oncol. 2015;16(3):257-265.
62. Brahmer J, Reckamp KL, Baas P, et al. Nivolumab versus docetaxel in advanced squamous-cell non-small-cell lung cancer. NEngl JMed. 2015; 373(2):123-135.

63. Thatcher N, Hirsch FR, Luft AV, et al. Necitumumab plus gemcitabine and cisplatin versus gemcitabine and cisplatin alone as first-line therapy in patients with stage IV squamous non-small-cell lung cancer (SQUIRE): an open-label, randomised, controlled phase 3 trial. Lancet Oncol. 2015;16(7):763-774.

64. Derman BA, Mileham KF, Bonomi PD, Batus M, Fidler MJ. Treatment of advanced squamous cell carcinoma of the lung: a review. Transl Lung Cancer Res. 2015;4(5):524-532.

65. Gandara DR, Hammerman PS, Sos ML, Lara PN, Hirsch FR. Squamous cell lung cancer: from tumor genomics to cancer therapeutics. Clin Cancer Res. 2015;21(10):2236-2243.

66. Herbst RS, Gandara DR, Hirsch FR, et al. Lung Master Protocol (LungMAP) - a biomarker-driven protocol for accelerating development of therapies for squamous cell lung cancer: SWOG S1400. Clin Cancer Res. 2015;21(7):1514-1524.

67. Ferrarotto R, Redman MW, Gandara DR, Herbst RS, Papadimitrakopoulou VA. Lung-MAP - framework, overview, and design principles. Chin Clin Oncol. 2015;4(3):36.

68. ClinicalTrials.gov [homepage on the Internet]. U.S. National Institutes of Health: search results. Available from: https://clinicaltrials.gov/ct2/ results?term=Afatinib+squamous+cell+lung $\&$ Search=Search. Accessed December 25, 2015.
Therapeutics and Clinical Risk Management

\section{Publish your work in this journal}

Therapeutics and Clinical Risk Management is an international, peerreviewed journal of clinical therapeutics and risk management, focusing on concise rapid reporting of clinical studies in all therapeutic areas, outcomes, safety, and programs for the effective, safe, and sustained use of medicines. This journal is indexed on PubMed Central, CAS,

\section{Dovepress}

EMBase, Scopus and the Elsevier Bibliographic databases. The manuscript management system is completely online and includes a very quick and fair peer-review system, which is all easy to use. Visit $\mathrm{http}: / / \mathrm{www}$.dovepress.com/testimonials.php to read real quotes from published authors. 